\title{
Basic studies leading to the development of an ultrahigh strength, high fracture toughness low-alloy steel
}

\author{
G MALAKONDAIAH, M SRINIVAS and P RAMA RAO* \\ Defence Metallurgical Research Laboratory, Kanchanbagh P O, Hyderabad 500258 , India \\ * Jawaharlal Nehru Centre for Advanced Scientific Research, IISc Campus, Bangalore \\ 560012 , India
}

\begin{abstract}
Ultrahigh strength steels have been used increasingly in recent years for critical aircraft and aerospace structural applications. In such applications, though materials performance is of prime consideration, cost and availability makes the low-alloy steels an attractive option. This paper describes the development of an ultrahigh strength NiSiCrCoMo low-alloy steel, supported by significant findings obtained from the basic studies that were aimed at understanding how solute additions influence fracture resistance of iron, with and without the presence of carbon. The results of the basic studies, in combination with the work of Garrison (1986) on a NiSiCr steel, have profitably been employed in the development of a NiSiCrCoMo low-alloy steel possessing a strength-toughness combination quite comparable to the highly alloyed 250 -grade maraging steel. Reproducibility of attractive strength and toughness properties has been established in tonnage scale melts. This steel, in the softened condition, has good formability and machinability. Weld parameters have also been established. The $\mathrm{NiSiCrCoMo}$ low-alloy steel thus meets the requirements of performance and cost rendering it an attractive option for advanced structural applications.
\end{abstract}

Keywords. Ultrahigh strength low-alloy steel; fracture toughness; alloy softening; tempered martensite embrittlement.

\section{Introduction}

Steels for several high-technology applications, such as aircraft and aerospace, need to possess ultrahigh strength coupled with high fracture toughness in order to meet the requirement of minimum weight while ensuring high reliability. In such applications, though materials performance is of prime consideration, cost and availability makes the low-alloy steels an attractive option. The commercial use of low-alloy steels for such applications has often been limited by their low fracture toughness. It is wellknown that increase in strength is generally accompanied by a decrease in toughness. Considerable research effort has been directed over the past two decades or so towards improving fracture toughness of low-alloy steels at yield strengths $\geqslant 1400 \mathrm{MPa}$. As recently reviewed by Tomita (1991), these efforts can broadly be classified into three methods, namely (i) thermal and thermomechanical treatments, (ii) control of sulphide inclusions and (iii) design of new alloys. Here we present the work carried out by us aimed at development of a low-alloy $\mathrm{NiSiCrCoMo}$ steel possessing strength-toughness combination quite comparable to highly alloyed 250grade maraging steel.

We embarked upon a research programme with the aim of understanding the fracture toughness behaviour of iron and its alloys, which constitute the basis for widely used engineering steels. Evaluation of fracture behaviour of iron-based solid solutions, with cobalt, molybdenum, nickel or silicon as solutes, was undertaken. To establish the influence of alloying additions in the presence of carbon, the studies were extended to $\mathrm{Fe}-\mathrm{C}-\mathrm{X}$ alloys. The understanding thus developed, in combination with 
the work of Garrison (1986) on a NiSiCr steel, has been profitably employed for the development of a NiSiCrCoMo low-alloy steel.

\section{Basic studies}

Solute additions to metals to form solid solutions invariably results in improvement in strength with a concomitant decrease in fracture resistance. There exists a fair amount of understanding as to how solutes influence strength of the alloys (Leslie 1972; Pickering 1978). However, understanding in regard to resistance to fracture, in comparable depth, is yet to evolve. To-date studies pertaining to the fracture resistance of iron and its solid solutions are limited and have been carried out in terms of either tensile ductility or impact transition temperature, which parameters do not always correlate well with the fracture toughness. In our work, the $J$-integral method was used for the measurement of ductile fracture toughness $J_{\text {IC }}$ of eight solid solution alloys of Armco iron containing cobalt, molybdenum, nickel or silicon at two levels of concentration. The studies were then extended to $\mathrm{Fe}-\mathrm{C}$ based alloys.

\subsection{Solid solution alloys of iron}

Solid solution alloys of iron with $\mathrm{Co}$, Mo or $\mathrm{Ni}$ at 0.5 and $5.0 \mathrm{wt} . \%$ and $\mathrm{Si}$ at 0.5 and $3.5 \mathrm{wt}$ \% concentrations were processed, the details of which are given elsewhere (Srinivas 1991). Armco iron, $\mathrm{Fe}-0.5 \mathrm{Co}, \mathrm{Fe}-5 \mathrm{Co}$ and $\mathrm{Fe}-0.5 \mathrm{Mo}$ exhibited stable crack extension while $\mathrm{Fe}-0.5 \mathrm{Ni}, \mathrm{Fe}-5 \mathrm{Ni}, \mathrm{Fe}-0-5 \mathrm{Si}, \mathrm{Fe}-3.5 \mathrm{Si}$ and $\mathrm{Fe}-5 \mathrm{Mo}$ showed cleavage instability during loading of precracked fracture toughness specimens (Srinivas et al 1994a). $J-R$ curve technique as well as critical stretch zone width were employed to derive $J_{\text {IC }}$ in the former case while in the latter case the value of $J$ at the onset of cleavage instability was taken as $J_{\mathrm{Q}}$ and subjected to validity checks. Fracture toughness $J_{\mathrm{IC}}$ data for the four binary alloys are presented in table 1 and plotted as a function of alloying content in

Table 1. Tensile, impact and fracture toughness properties for Armco iron and its binary alloys.

\begin{tabular}{|c|c|c|c|c|c|c|c|c|}
\hline Material & $\begin{array}{l}\text { Grain } \\
\text { size } \\
(\overline{\mathrm{L}} / \mu \mathrm{m})\end{array}$ & $\begin{array}{c}\text { Yield } \\
\text { stress } \\
\text { (MPa) }\end{array}$ & $\begin{array}{c}\text { UTS } \\
\text { (MPa) }\end{array}$ & $n$ & $\begin{array}{l}\text { CVN impact } \\
\text { energy } \\
\text { at } R T \\
\text { (J) }\end{array}$ & $\begin{array}{c}\text { DBTT* }^{*} \\
(\mathrm{~K})\end{array}$ & $\begin{array}{c}J_{1 \mathrm{c}} \\
\left(\mathrm{kJ} / \mathrm{m}^{-2}\right)\end{array}$ & $\begin{array}{l}\text { Notch } \\
\text { yield } \\
\text { ratio** }\end{array}$ \\
\hline Armco iron & 78 & 189 & 296 & $0-29$ & 250 & 243 & 170 & - \\
\hline Armco iron & 118 & 180 & 296 & 0.28 & 260 & 251 & 140 & $2 \cdot 5$ \\
\hline $\mathrm{Fe}-0.5 \mathrm{Si}$ & 125 & 225 & 385 & $0-21$ & 8 & 330 & 97 & - \\
\hline $\mathrm{Fe}-3.5 \mathrm{Si}$ & 140 & 423 & 541 & 0.15 & 6 & 405 & 42 & $1 \cdot 5$ \\
\hline $\mathrm{Fe}-0.5 \mathrm{Mo}$ & 125 & 187 & 359 & 0.27 & 52 & 276 & 112 & - \\
\hline $\mathrm{Fe}-5.0 \mathrm{Mo}$ & 120 & 212 & 385 & 0.22 & 40 & 285 & 102 & - \\
\hline $\mathrm{Fe}-0.5 \mathrm{Ni}$ & 125 & 195 & 335 & 0.25 & 8 & 353 & 59 & - \\
\hline $\mathrm{Fe}-5.0 \mathrm{Ni}$ & 80 & 257 & 386 & 0.21 & 15 & 423 & 80 & - \\
\hline $\mathrm{Fe}-0.5 \mathrm{Co}$ & 130 & 110 & 290 & $0-30$ & 210 & 253 & 162 & - \\
\hline $\mathrm{Fe}-5-0 \mathrm{Co}$ & 125 & 130 & 293 & 0.35 & 270 & 263 & 187 & $3 \cdot 7$ \\
\hline
\end{tabular}

*20 J (15 ft. lb) criterion

** Ratio of notch tensile strength and yield strength 


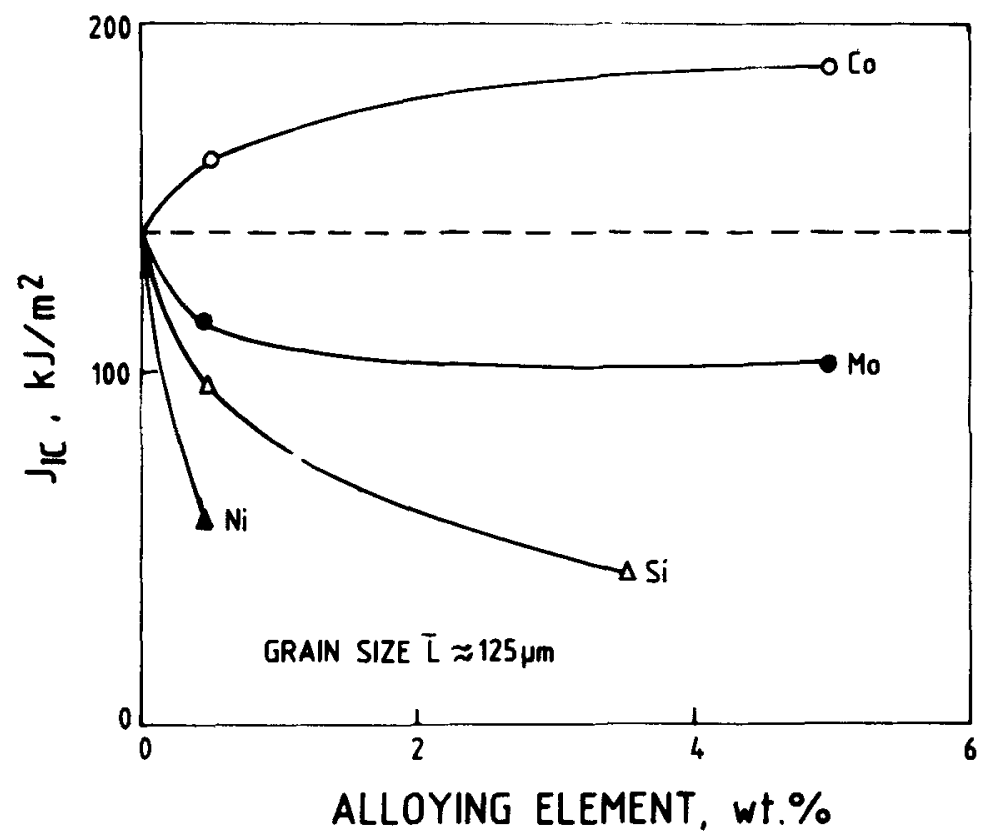

Figure 1. Influence of solute additions on fracture toughness of Armco iron at a constant grain size of $125 \mu \mathrm{m}$.

figure 1. The notable observation is that cobalt imparts to Armco iron significant improvement in fracture toughness. On the other hand, $\mathrm{Si}$ and $\mathrm{Ni}$ have an increasing degree of deleterious effect on Armco iron in that order, with the least effect being noticed with Mo (Srinivas et al 1991a, 1994a).

The large decrease in $J_{\mathrm{IC}}$ with silicon and higher molybdenum concentration is explained on the basis of a change in fracture mode from ductile to cleavage as a result of stress concentration ahead of the crack tip reaching the cleavage fracture stress. On the other hand, the loss in fracture toughness with nickel addition is attributed to sulphur segregation at grain boundaries which results in pockets of intergranular fracture.

$\mathrm{Mo}, \mathrm{Ni}$ or Si increases the yield strength (YS) of iron. On the other hand, cobalt lowers the yield strength of iron, with no observable effect on ultimate tensile strength (UTS) (table 1). The extent of reduction in yield strength (alloy softening) was seen to decrease with increasing cobalt content. Through secondary ion mass spectroscopy (SIMS), experimental evidence has been obtained, for the first time, for the suggestion that the 'scavenging' of interstitials (Rees et al 1951; Stoloff et al 1965; Ravi and Gibala 1969; Smialek et al 1970; Pink et al 1980; Ishii et al 1984) leads to alloy softening. Ion images for Armco iron, figures $2 a$ and $2 b$, clearly indicate that the interstitial carbon is homogeneously distributed in the solution. On the other hand, $\mathrm{C}^{-}$and $\mathrm{CN}^{-}$ion images for $\mathrm{Fe}-5 \mathrm{Co}$ alloy, figures $2 \mathrm{c}$ and $2 \mathrm{~d}$, clearly reveal segregation of carbon and nitrogen at the grain boundaries. It was also observed through yield stress dependence on grain size that the Hall-Petch constants $\sigma_{\mathrm{o}}$ and $k_{\mathrm{y}}$ substantiate SIMS observations (Srinivas et al 1994a). 
The increase in $J_{\mathrm{IC}}$ of Armco iron due to cobalt addition is primarily attributable to the increase in the strain hardening exponent $n$. The critical plastic zone size increases with increasing $n$. Furthermore, increase in $n$ results in slip dispersal and reduces the void growth rate. Increased $n$ as a result of cobalt addition is therefore expected to delay void nucleation and decrease the void growth rate. It thus appears that cobalt addition toughens iron by influencing the energy spent in the plastic zone formation as well as in the subsequent stages of the ductile fracture process, namely void nucleation, growth and coalescence of ductile fracture. If the lowering of yield strength
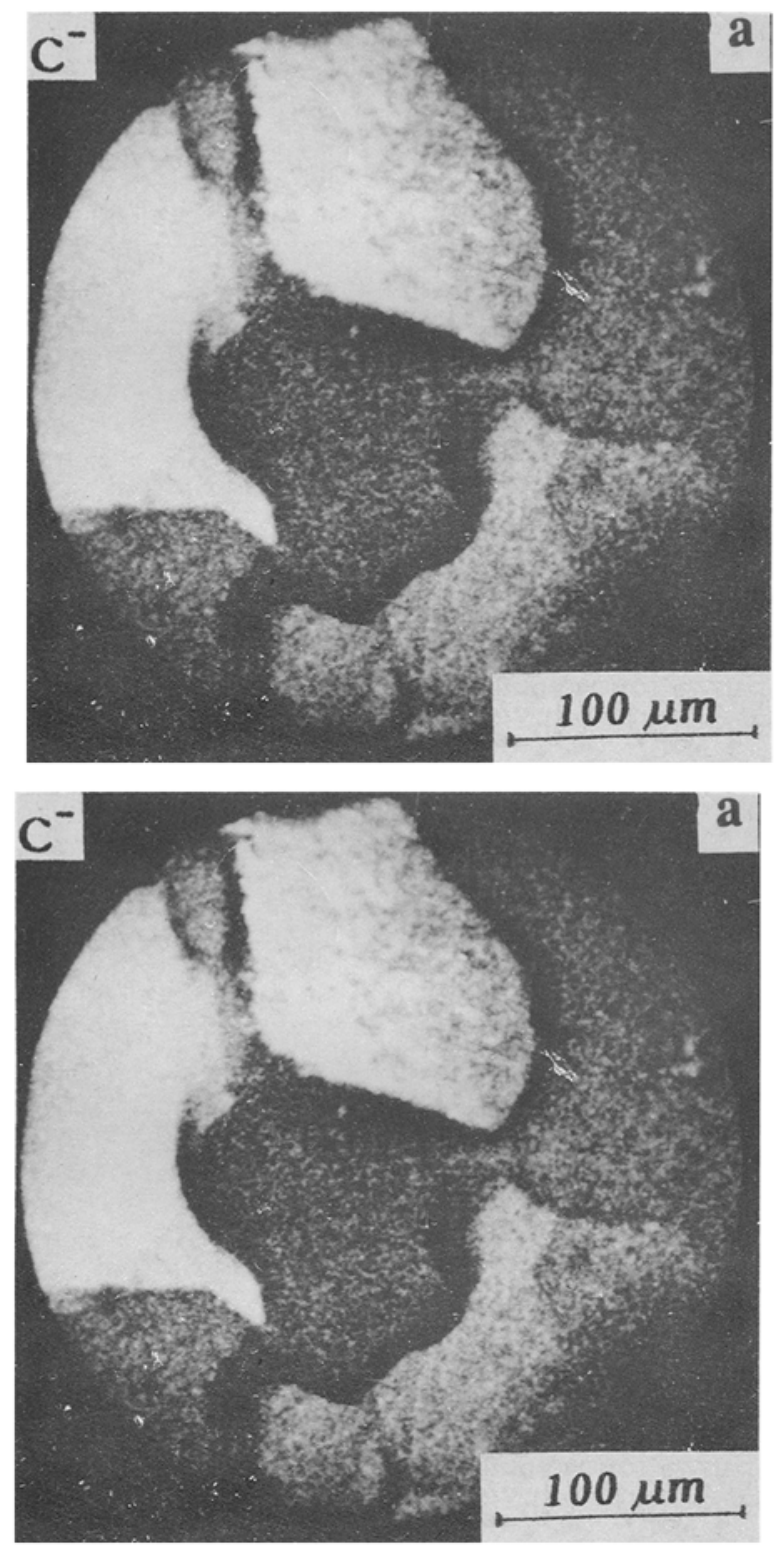

Figure 2a-b. 

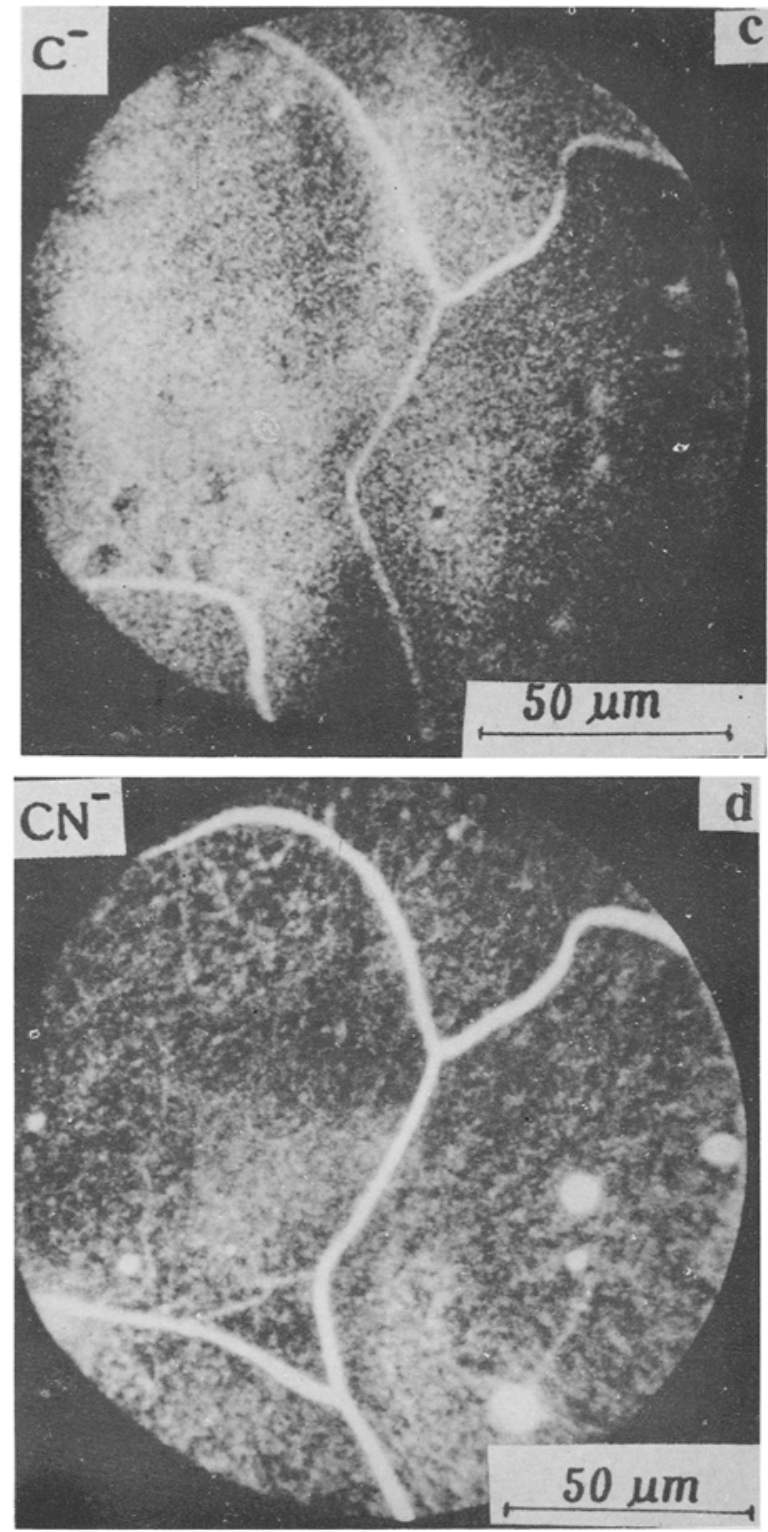

Figure 2. SIMS ion images showing $(\mathbf{a}, \mathbf{b})$ uniform distribution of interstitials in Armco iron, and $(\mathbf{c}, \mathbf{d})$ scavenging of interstitials to grain boundaries in $\mathrm{Fe}-5 \mathrm{Co}$ alloy.

by cobzlt addition to iron were to be the prime reason for the enhancement of $J_{1 \mathrm{C}}$, addition of $0.5 \% \mathrm{Co}$, which reduced the yield strength by $40 \%$ as compared with a $25 \%$ decrease with $5 \%$ Co addition, should have resulted in a larger increase in $J_{\text {IC }}$. Contrary to these expectations, a $5 \%$ cobalt addition caused a higher increase in $J_{\mathrm{IC}}$ of iron $(35 \%)$. Although $\mathrm{Fe}-\mathrm{Co}$ alloys have lower yield strengths than Armco iron, the flow stress builds up rapidly as a result of higher strain hardening rate at the early stages of plastic deformation. 
A new approach has been proposed (Srinivas et al 1994b) to the calculation of $J_{\text {IC }}$ in terms of the critical strain criterion model, originally developed by Rice and Johnson (1970) and Ritchie and Thompson (1985), for engineering alloys having a substantial volume fraction of second phase particles. The sequence of events leading to crack initiation is assumed to be as follows. As soon as the pre-cracked sample is loaded in tension under a monotonically increasing load, extensive blunting of the crack tip occurs. The crack blunting process is completed, leading to a constant stretch zone width (SZW), before the void nucleation and growth occur at a characteristic distance $l_{\mathrm{c}}$ from the blunted crack tip. The mechanism of void nucleation ahead of the blunted crack and also the characteristic distance $l_{\mathrm{c}}$ of the void from the crack tip have been determined for a single phase material, for the first time, through a careful examination of the interrupted fracture toughness test specimens (Srinivas 1991; Srinivas et al 1994b). The proposed approach not only incorporates the experimentally measured $l_{\mathrm{c}}$ values but also the plastic flow related energy dissipation in the Hutchinson-Rice-Rosengren zone beyond the process zone. Theoretically predicted $J_{\mathrm{IC}}$ values are compared in figure 3 with those derived experimentally. Figure 3 also includes data on Armco iron and nickel derived over the temperature range $298-673 \mathrm{~K}$ (Srinivas et al 1991a). It is clear

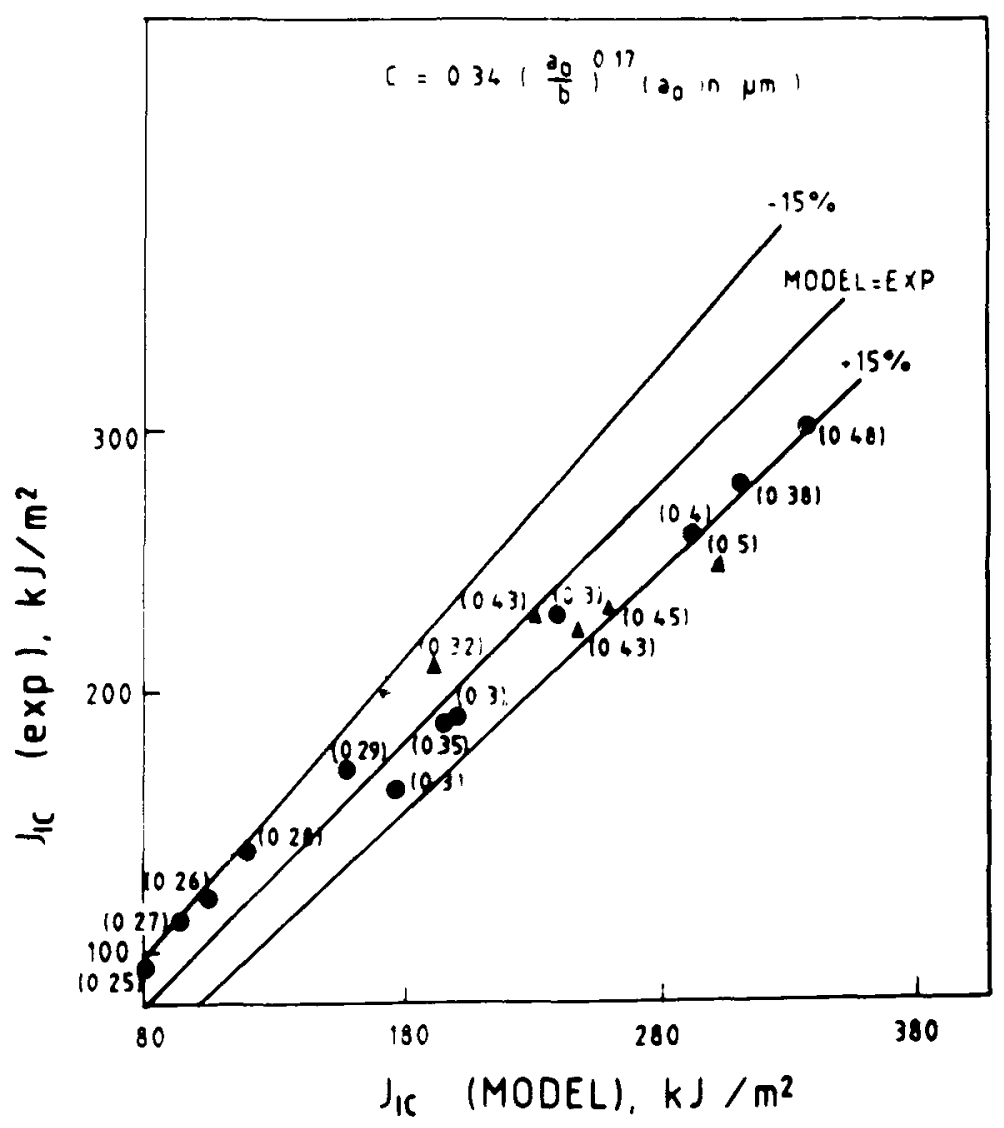

Figure 3. A comparison between experimentally measured and model predicted $J_{\mathrm{IC}}$ values. 
from figure 3 that the proposed method estimates reasonably well (to within $\pm 15 \%$ ) the ductile initiation fracture toughness $J_{\mathrm{IC}}$ of single phase materials exhibiting a wide range of values $\left(100-300 \mathrm{~kJ} / \mathrm{m}^{2}\right)$.

\section{$2.2 \mathrm{Fe}-\mathrm{C}-\mathrm{X}$ alloys}

The studies on $\mathrm{Fe}-\mathrm{C}-\mathrm{X}$ alloys have significantly revealed that the beneficial effect of cobalt on $J_{\mathrm{IC}}$ of iron is even more pronounced in the presence of carbon (Srinivas et al 1991b). The strength and toughness properties of $\mathrm{Fe}-0.2 \mathrm{C}, \mathrm{Fe}-0.2 \mathrm{C}-5 \mathrm{Co}$ and $\mathrm{Fe}-$ $0.2 \mathrm{C}-5 \mathrm{Ni}$ alloys are compared in table 2 . A $5 \%$ cobalt addition does not influence significantly the strength behaviour of $\mathrm{Fe}-0.2 \mathrm{C}$ alloy. On the other hand, a $5 \%$ nickel addition appreciably increases the strength and reduces ductility and work hardening exponent. The addition of $5 \%$ cobalt significantly enhances $(80 \%) J_{1 C}$ of $\mathrm{Fe}-0.2 \mathrm{C}$ alloy, while the addition of $5 \%$ nickel increases the same marginally $(18 \%)$. Nickel, generally considered to be a beneficial element in the presence of carbon is seen to influence dramatically the impact toughness with only a marginal effect on $J_{1 \mathrm{c}}$. On the other hand, cobalt addition, with no observable effect on impact toughness, causes significant improvement in $J_{\mathrm{IC}}$. These results further suggest that there is no one-toone correlation between impact toughness and static fracture toughness for this class of alloys.

Similar findings have been reported in recent years (Ritchie et al 1976; Lin et al 1986) although, on the other hand, there is a fairly widespread use of correlations between impact toughness and fracture toughness. High temperature austenitizing treatment at $1473 \mathrm{~K}$ results in a two-fold increase in fracture toughness $K_{\mathrm{IC}}$ of AISI 4340 steel but gives rise to inferior charpy impact energy as compared to conventional $1143 \mathrm{~K}$ austenitizing treatment (Ritchie et al 1976). This behaviour was shown to be independent of shear lip energy and the variation in strain rate imposed by $K_{\mathrm{IC}}$ and impact tests. Such an effect was found to result from the differing response of each microstructure in regard to the influence of notch root radius on toughness. Ritchie $e t$ al (1976) proposed that failure occurs when the maximum tensile stress exceeds the critical fracture stress $\sigma_{F}$ over a characteristic distance ahead of a sharp crack $\left(K_{\mathrm{IC}}\right)$ or at the elastic-plastic interface ahead of a rounded notch (impact). Fracture toughness of $1473 \mathrm{~K}$ structure is higher because the characteristic distance (associated with coarser grain size) is larger while the higher impact toughness of $1143 \mathrm{~K}$ structure is a result of larger fracture stress. On the other hand, the reasons for the dramatic effect of nickel on impact toughness observed in the present study could be traced to alloy softening at high strain rates prevailing under impact conditions (Srivinas et al 1991c),

Table 2. Tensile, impact and fracture toughness properties of $\mathrm{Fe}-\mathrm{C}-\mathrm{X}$ alloys.

\begin{tabular}{|c|c|c|c|c|c|}
\hline Material & $\begin{array}{c}\mathbf{Y S} \\
(\mathrm{MPa})\end{array}$ & $\begin{array}{c}\text { UTS } \\
\text { (MPa) }\end{array}$ & $\begin{array}{c}\text { El. } \\
(25 \mathrm{~mm} \mathrm{GL}) \\
(\%)\end{array}$ & $\begin{array}{c}\text { CVN } \\
\text { impact } \\
\text { energy }(J)\end{array}$ & $\begin{array}{c}J_{\mathrm{IC}} \\
\left(\mathrm{kJ} / \mathrm{m}^{2}\right)\end{array}$ \\
\hline $\mathrm{Fe}-0.2 \mathrm{C}$ & 244 & 370 & 44 & 16 & 130 \\
\hline $\mathrm{Fe}-0 \cdot 2 \mathrm{C}-5 \mathrm{Co}$ & 242 & 409 & 47 & 15 & 232 \\
\hline $\mathrm{Fe}-0-2 \mathrm{C}-5 \mathrm{Ni}$ & 297 & 467 & 37 & 120 & 153 \\
\hline
\end{tabular}


as also suggested by Jolley (1968) and Petch (1987). The microstructural features, namely ferrite grain size and the volume fraction of pearlite were maintained nearly the same in all the three $\mathrm{Fe}-\mathrm{C}$ based alloys under consideration.

\section{Development of NiSiCrCoMo steel}

It is evident from the foregoing that cobalt toughens iron, and even more positively in the presence of carbon. In our efforts to arrive at a new alloy chemistry that possesses improved fracture toughness at ultrahigh strength levels, cobalt addition was made to Garrison NiSiCr steel.

\subsection{Cobalt modified NiSiCr steels}

Silicon is a solid solution strengthening element. It is known to delay tempering and shift tempered martensite embrittlement to higher temperatures, which features enable retention of ultrahigh strength levels even after tempering at relatively higher temperatures. Silicon is also known to influence sulphide distribution in the presence of nickel (Garrison 1986). Silicon refines sulphide particle size and increases sulphide spacing and thereby causes an increase in fracture toughness by rendering the fracture

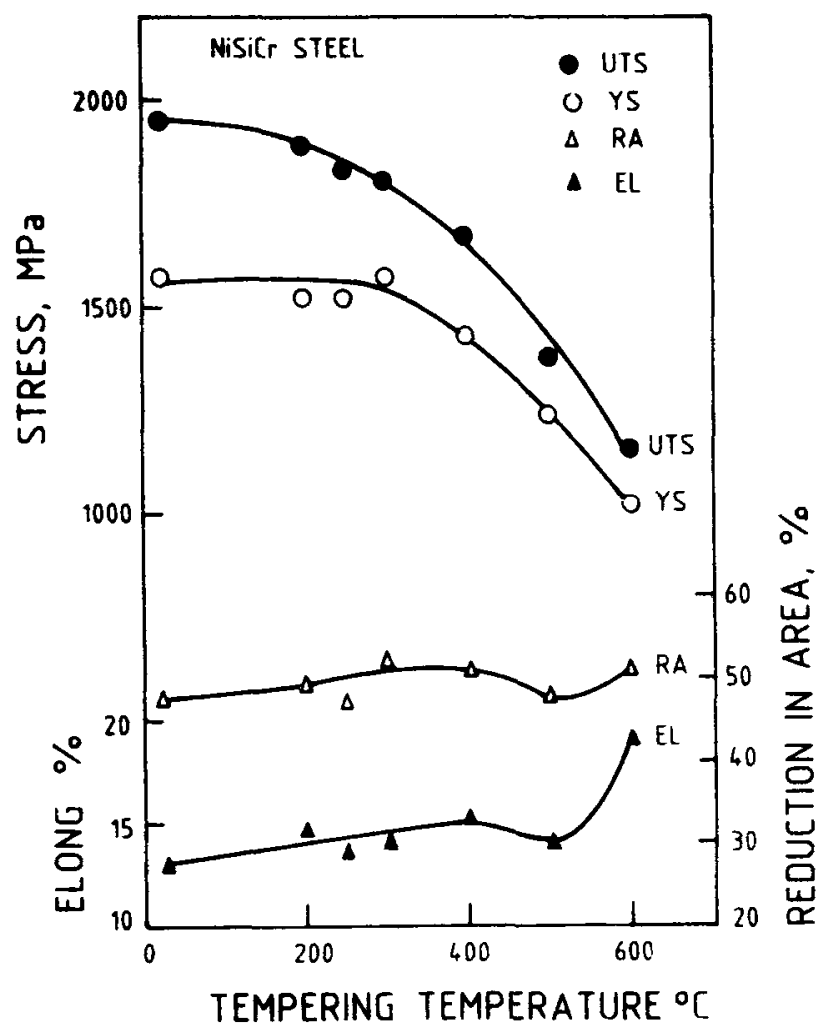

Figure 4. Tensile properties of $\mathrm{NiSiCr}$ steel as a function of tempering temperature. 
process that involves void nucleation, growth and linkage more difficult. In view of these observations, Garrison (1986) NiSiCr steel containing high silicon has been chosen as the base material.

The variation of strength with tempering temperature (figure 4) shows that the $\mathrm{NiSiCr}$ steel retains high strength up to $250^{\circ} \mathrm{C}$. Beyond about $300^{\circ} \mathrm{C}$, there occurs a steep fall in strength, which is also accompanied by a loss in ductility. A trough in ductility variation with tempering temperature occurs in the temperature range 400 to $600^{\circ} \mathrm{C}$. The impact energy at room temperature increases with tempering temperature up to around $300^{\circ} \mathrm{C}$, beyond which a steep fall occurs, with a minimum at $500^{\circ} \mathrm{C}$ (figure 5). It is evident from the data presented in figures 4 and 5 that the steel develops an optimum combination of strength and impact toughness in the $250^{\circ} \mathrm{C}$ tempered condition. Accordingly, fracture toughness and ductile-to-brittle transition temperature (DBTT) were evaluated for the steel in the $250^{\circ} \mathrm{C}$ tempered condition. Fracture toughness tests conducted according to ASTM standard E399 yielded $K_{\text {IC }}$ of $103 \mathrm{MPa} / \mathrm{m}$. The impact toughness in the $250^{\circ} \mathrm{C}$ tempered condition is plotted against test temperature in figure 6 . The $20 \mathrm{~J}$ criterion yields a DBTT of $-100^{\circ} \mathrm{C}$. Mechanical properties of the base Garrison NiSiCr steel subjected to an optimum treatment of $250^{\circ} \mathrm{C}$ tempering are summarized in table 3.

Transmission electron microscopy (TEM) and Auger electron spectroscopy (AES) studies have revealed (Malakondaiah et al 1994) that the loss in ductility and impact toughness of $\mathrm{NiSiCr}$ steel in the tempering temperature range 350 to $600^{\circ} \mathrm{C}$ is due to the simultaneous occurrence of tempered martensite embrittlement (TME) and tempered embrittlement (TE). It is now well established that TME occurs in low-alloy

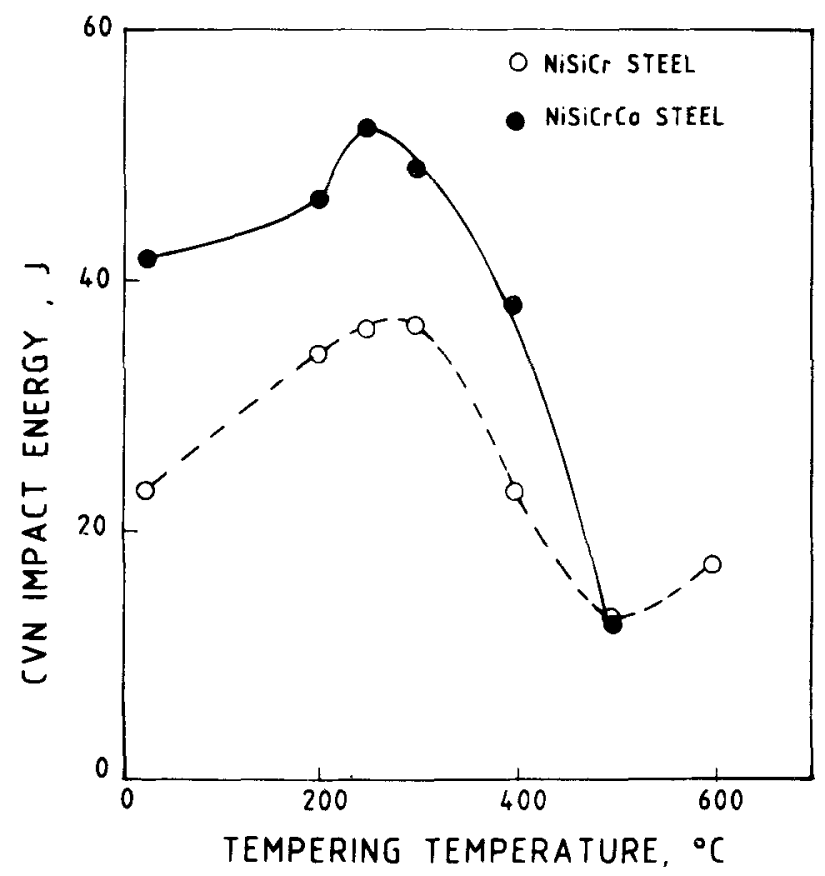

Figure 5. Charpy V-notch impact energy as a function of tempering temperature for $\mathrm{NiSiCr}$ and NiSiCrCo steels. 


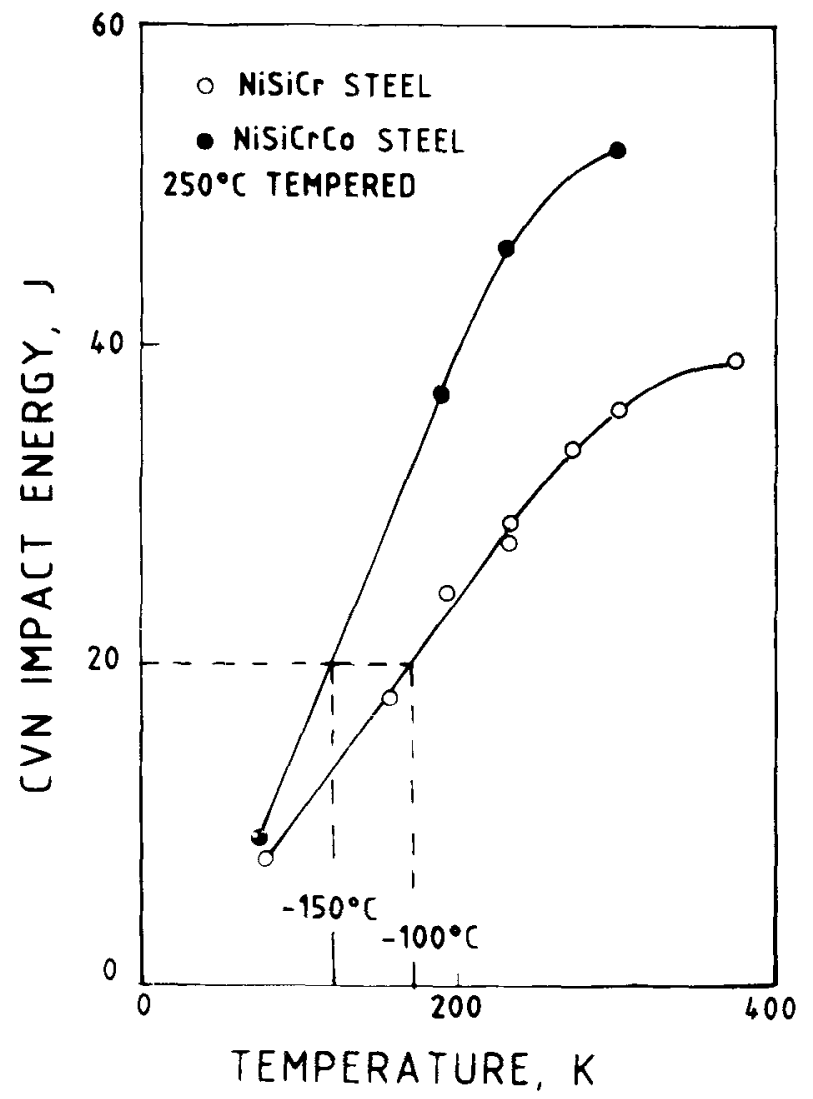

Figure 6. Variation of Charpy V-notch impact energy with test temperature for $\mathrm{NiSiCr}$ and $\mathrm{NiSiCrCo}$ steels in $250^{\circ} \mathrm{C}$ tempered condition.

Table 3. Mechanical properties of steels developed in the present study in the optimum heat treated condition.

\begin{tabular}{lccccc}
\hline Material & $\begin{array}{c}\text { YS } \\
\text { (MPa) }\end{array}$ & $\begin{array}{c}\text { UTS } \\
(\mathrm{MPa})\end{array}$ & $\begin{array}{c}\text { RA } \\
(\%)\end{array}$ & $\begin{array}{c}\text { CVN impact } \\
\text { energy at RT } \\
(\mathrm{J})\end{array}$ & $\begin{array}{c}K_{\mathrm{IC}} \\
(\mathrm{MPa} \sqrt{\mathrm{m}})\end{array}$ \\
\hline NiSiCr & 1550 & 1825 & 47 & 36 & 103 \\
NiSiCrCo & 1360 & 1670 & 50 & 52 & 140 \\
NiSiCrMo & 1648 & 1904 & 48 & 35 & 102 \\
NiSiCrCoMo & 1530 & 1890 & 48 & 34 & 120 \\
\hline
\end{tabular}

steels when tempered in the temperature rarge 250 to $400^{\circ} \mathrm{C}$. A higher temperature range of 350 to $600^{\circ} \mathrm{C}$ for $\mathrm{NiSiCr}$ steel is understandable as silicon is known to shift TME to higher temperatures. TEM carried out on 250,500 and $600^{\circ} \mathrm{C}$ tempered specimens revealed the presence of interlath-retained austenite in the $250^{\circ} \mathrm{C}$ tempered condition, transformation of retained austenite to carbides in the $500^{\circ} \mathrm{C}$ tempered condition and coarse interlath carbides in the $600^{\circ} \mathrm{C}$ tempered condition (figure 7). 

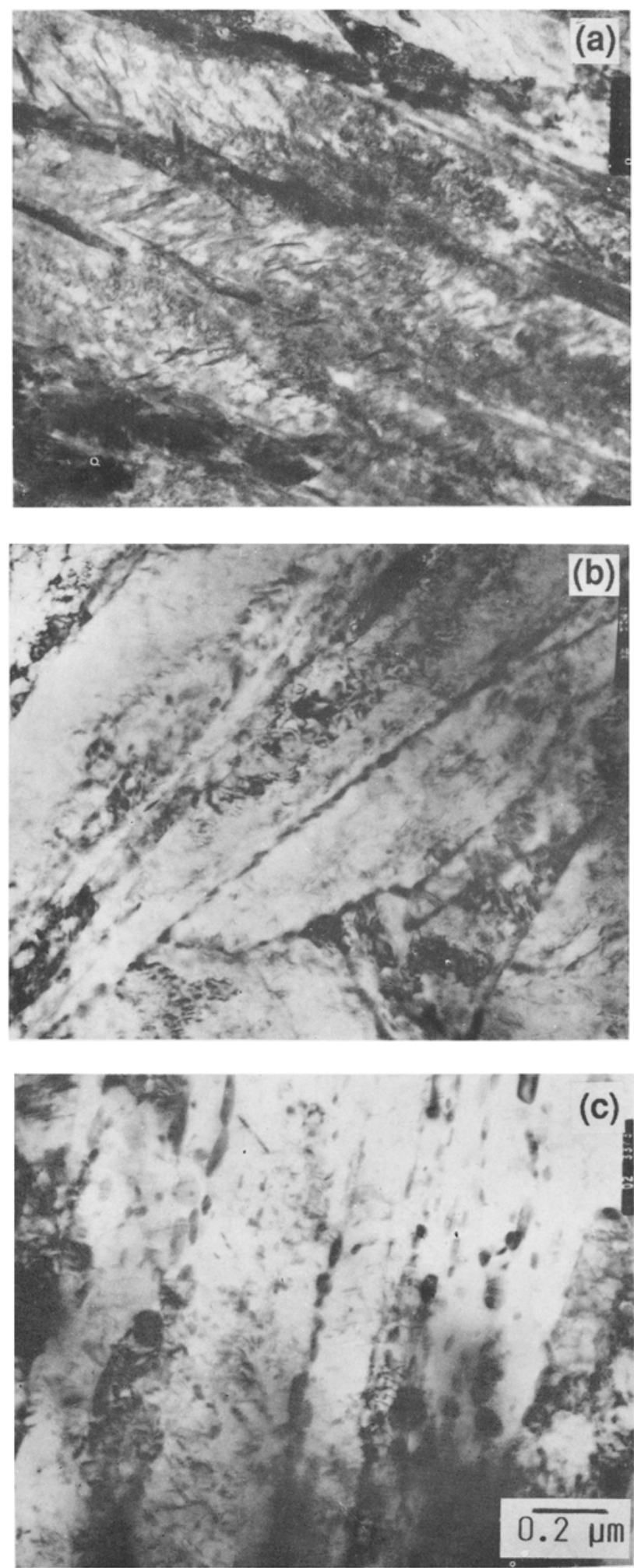

Figure 7. TEM micrographs of $\mathrm{NiSiCr}$ steel tempered at (a) $250^{\circ} \mathrm{C}$ and (b) $500^{\circ} \mathrm{C}$ showing interlath retained austenite and carbide stringers respectively. (c) Coarse interlath carbides are seen in the $600^{\circ} \mathrm{C}$ tempered condition. 
Further, AES carried out on $500^{\circ} \mathrm{C}$ tempered condition revealed segregation of phosphorous, which was absent in the as-quenched condition, suggesting occurrence of temper embrittlement.

Cobalt addition was made to the base $\mathrm{NiSiCr}$ steel to achieve further improvements in fracture toughness. The tempering behaviour of $\mathrm{NiSiCrCo}$ steel, shown in figure 8 , reveals that the steel retains higher strength up to $300^{\circ} \mathrm{C}$, as against $250^{\circ} \mathrm{C}$ observed with $\mathrm{NiSiCr}$ steel. Ductility shows a trough in the tempering temperature range 400 to $600^{\circ} \mathrm{C}$. The impact energy data included in figure 5 reveals that the impact toughness increases with tempering temperature up to $250^{\circ} \mathrm{C}$, beyond which a steep fall occurs. It is evident from figures 5 and 8 that $\mathrm{NiSiCrCo}$ steel, in a manner similar to that observed with the base $\mathrm{NiSiCr}$ steel, develops an optimum combination of strength and impact toughness in the $250^{\circ} \mathrm{C}$ tempered condition. Fracture toughness tests carried out in this optimum condition yielded a $K_{\text {IC }}$ of $140 \mathrm{MPa} \sqrt{\mathrm{m}}$. The $20 \mathrm{~J}$ criterion yields a DBTT of $-150^{\circ} \mathrm{C}$ (figure 6). Mechanical properties of $\mathrm{NiSiCrCo}$ steel in $250^{\circ} \mathrm{C}$ tempered condition are included in table 3. A significant increase in fracture toughness is seen with accompanying loss in strength. However, the loss in strength is not in proportion to the increase in fracture toughness. A $40 \%$ increase in fracture toughness is seen while the loss in strength is around 10\%. More than $40 \%$ increase in impact toughness is also evident (table 3 ).

The increase in fracture toughness with an accompanying decrement in strength with cobalt addition to base steel is in line with the observations made on cobalt

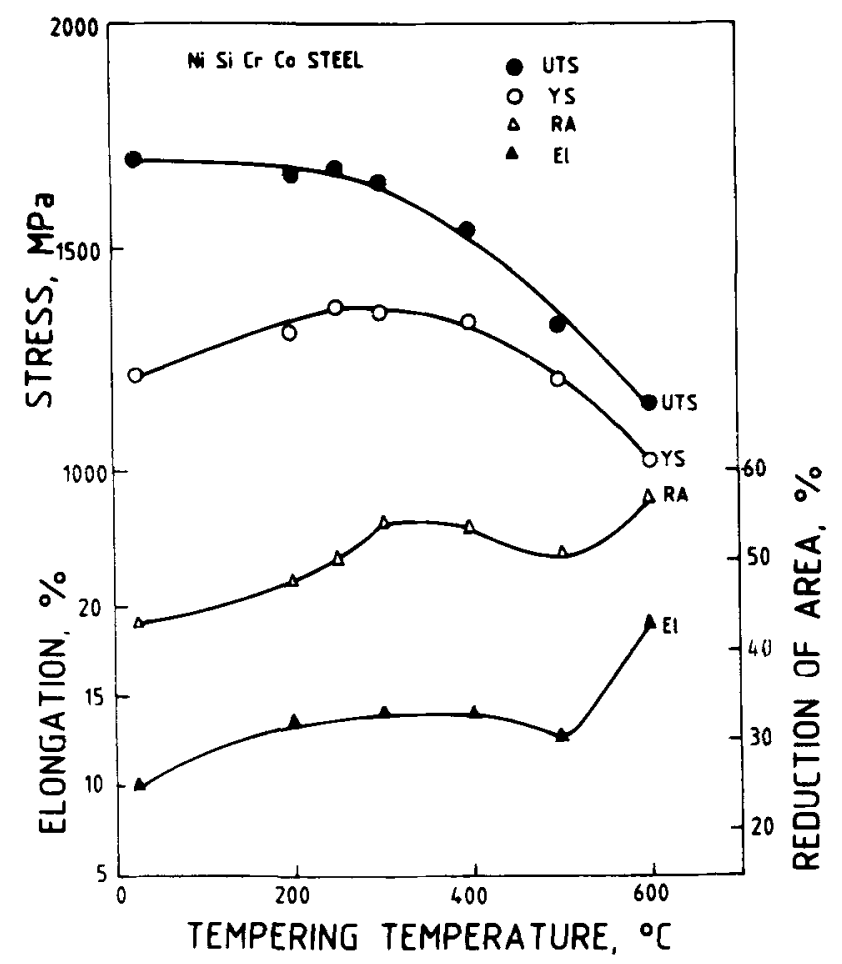

Figure 8. Tensile properties of $\mathrm{NiSiCrCo}$ steel as a function of tempering temperature. 


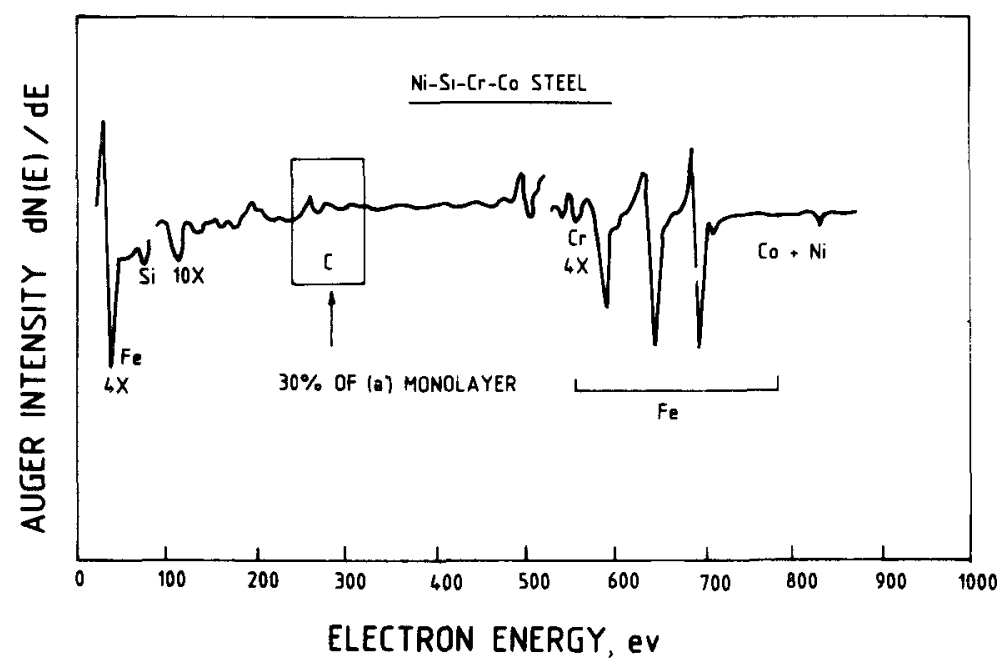

Figure 9. Scanning Auger spectrum showing carbon segregation at grain boundaries in NiSiCrCo steel.

additions to Armco iron (Srinivas et al 1994a). Microsegregation studies carried out on NiSiCrCo steel using a scanning auger microscope show segregation of carbon to the grain boundaries (figure 9). The increase in fracture toughness with cobalt addition is attributable to the segregation of carbon to the grain boundaries, thus increasing the cohesive strength of the grain boundary and rendering the crack initiation process much more difficult (Olson 1990; Misra and Rama Rao 1993).

To build up strength in the presence of cobalt in the base $\mathrm{NiSiCr}$ steel, molybdenum addition was resorted to. The studies on iron based solid solutions have shown that, while molybdenum is a solid solution strengthener, the fracture toughness of Armco iron is only marginally lowered as a result of molybdenum addition, below a certain level of concentration. The influence of molybdenum on the base $\mathrm{NiSiCr}$ steel was therefore studied. The study has interestingly revealed that the addition of molybdenum to the base $\mathrm{NiSiCr}$ steel leads to an increase in yield and ultimate tensile strength with negligible reduction in fracture toughness (table 3). The increase in yield strength is as much as 7\% while the increase in UTS is around $5 \%$.

As a follow-up, molybdenum addition was made to the cobalt containing steel. To optimize the composition further, melts with varying content of Co and Mo were taken and processed. The tempering behaviour of each steel was studied and the optimum property combination was established. The fracture toughness of the optimized NiSiCrCoMo steel is nearly $15 \%$ higher than that of the base Garrison $\mathrm{NiSiCr}$ steel at a matching strength level (table 3). The transmission electron micrograph corresponding to the optimum condition, shown in figure 10 , shows lightly tempered lath martensitic structure. SIMS studies carried out on $\mathrm{NiSiCrCoMo}$ steel in the optimized condition pointed to carbon segregation to grain boundaries (figure 11) reinforcing the suggestion that grain boundary carbon contributes to enhanced fracture toughness, observed in the results on binary $\mathrm{Fe}-\mathrm{Co}$ alloys, even when the steel is a complex composition of six alloying elements. 


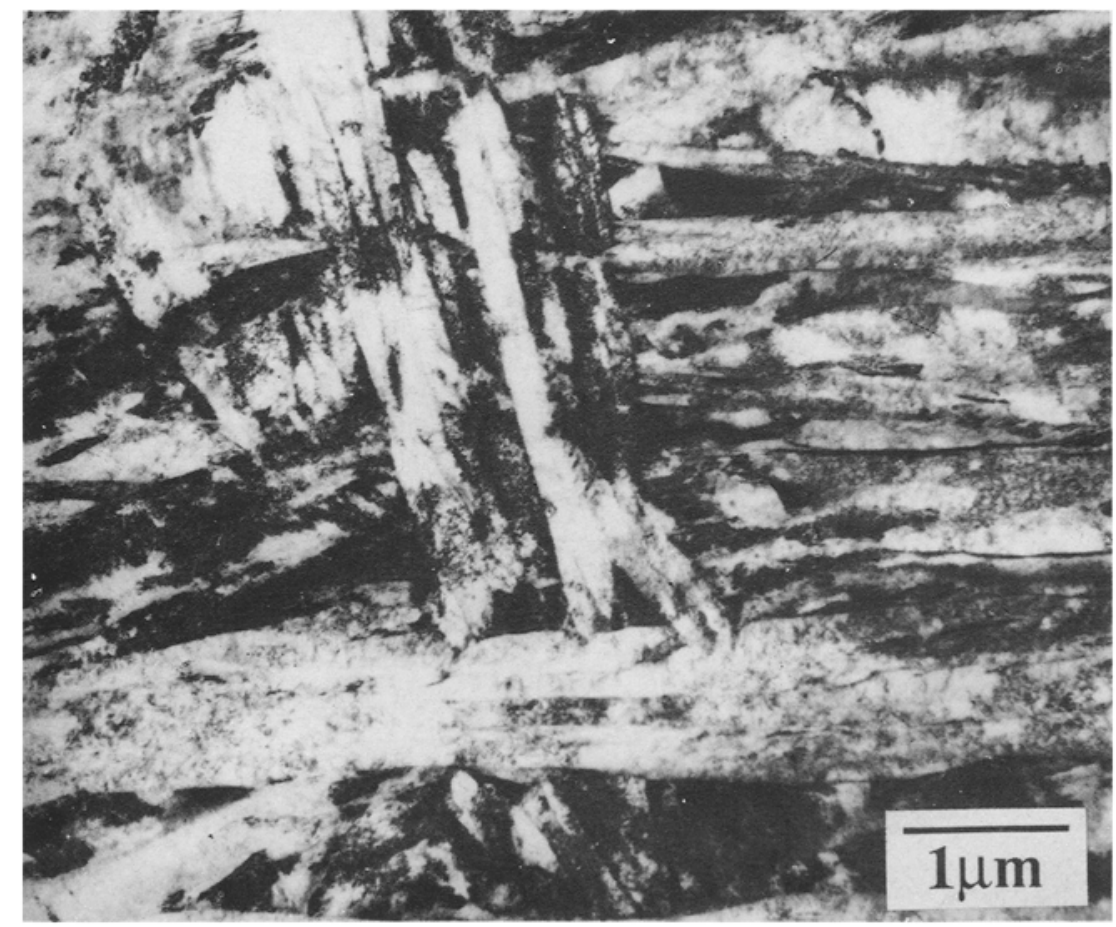

Figure 10. TEM micrograph of NiSiCrCoMo steel showing lightly tempered lath martensitic structure in the optimum heat treated condition.

\subsection{Comparison with other ultrahigh strength steels}

The properties of NiSiCr, NiSiCrCo, NiSiCrMo and NiSiCrCoMo steels are compared in figure 12 with those of the low-alloy steels AISI 4340, 15CDV6 and D6ac, and highly alloyed HP 9-4-30 and maraging steels. Figure 12 shows the range of properties attainable with low-alloy quenched and tempered steels and $18 \mathrm{Ni}$ maraging steels as two separate bands. Among the three low-alloy steels under consideration, namely 15CDV6, AISI 4340 and D6ac, the properties of D6ac steel that was developed for aircraft and missile structural applications fall in the maraging steel regime. While the strength-toughness combination of the base Garrison NiSiCr steel is quite comparable to that of D6ac steel, the cobalt and molybdenum containing NiSiCrCoMo steel possesses properties superior to those of D6ac steel. The $\mathrm{NiSiCrCoMo} \mathrm{steel} \mathrm{is} \mathrm{also} \mathrm{superior} \mathrm{to} \mathrm{HP} \mathrm{9-4-30} \mathrm{in} \mathrm{terms} \mathrm{of} \mathrm{strength.} \mathrm{The} \mathrm{strength-}$ toughness data for $\mathrm{NiSiCrCo}$ and $\mathrm{NiSiCrCoMo} \mathrm{steels} \mathrm{fall} \mathrm{in} \mathrm{the} \mathrm{upper} \mathrm{bound} \mathrm{range}$ for 250 -grade maraging steel, with a total alloying content in excess of $30 \%$.

\subsection{Reproducibility of properties of $\mathrm{NiSiCrCoMo} \mathrm{steel} \mathrm{on} \mathrm{tonnage} \mathrm{scale}$}

Two 5 ton capacity melts of NiSiCrCoMo steel were taken and processed by Mishra Dhatu Nigam Limited (MIDHANI), a special alloy undertaking. Electric arc melting, followed by vacuum arc refining process, was employed. The mechanical properties of 


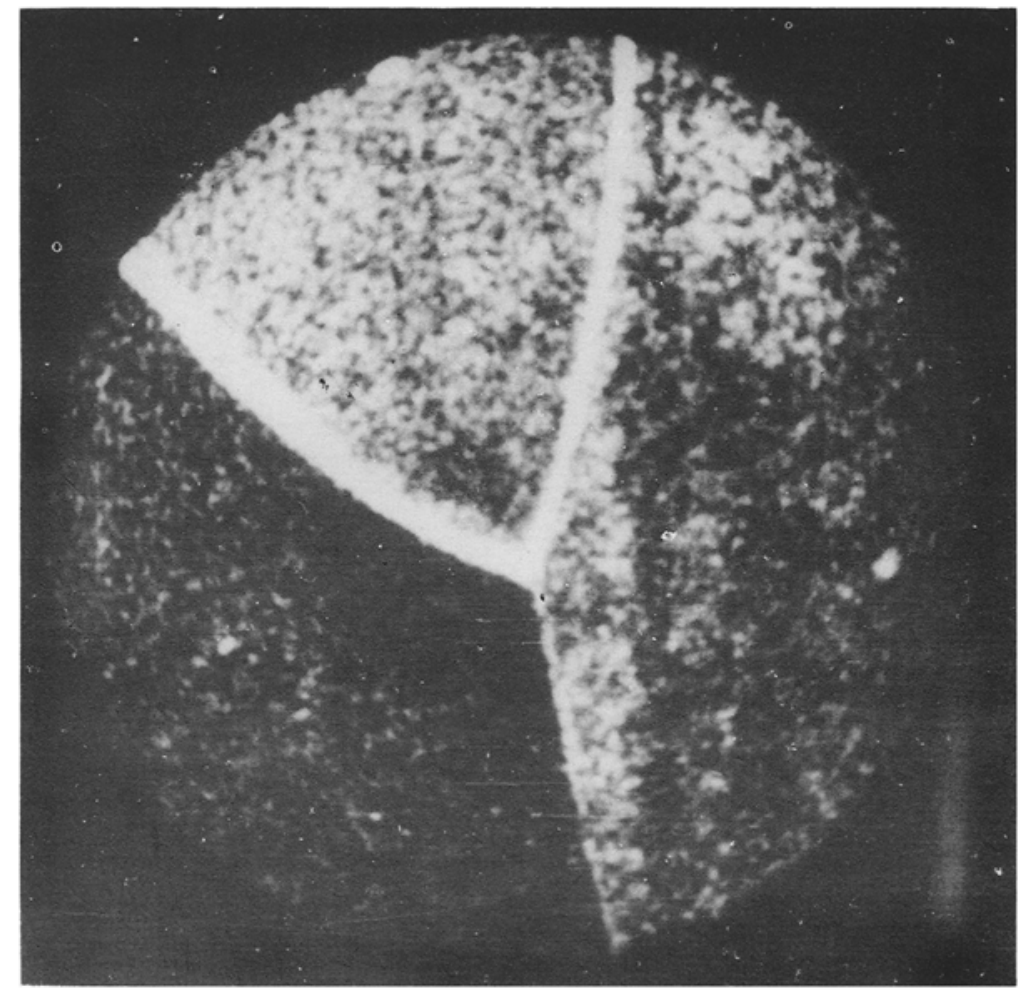

Figure 11. SIMS ion image showing carbon segregation to grain boundaries in $\mathrm{NiSiCrCoMo} \mathrm{steel.}$

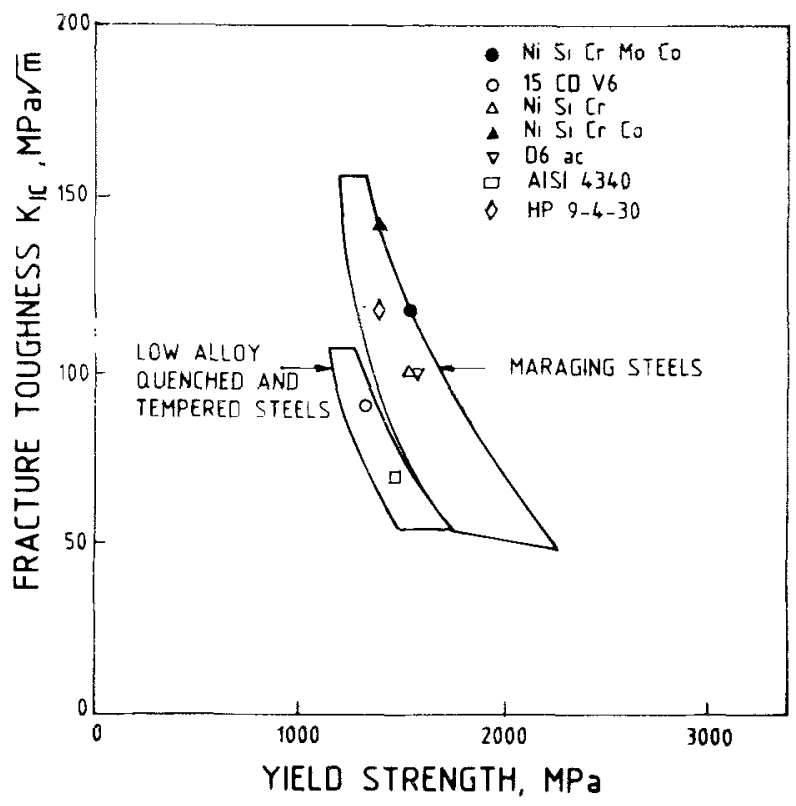

Figure 12. Fracture toughness vs yield strength for various ultrahigh strength steels. 
Table 4. Mechanical properties of NiSiCrCoMo steel.

\begin{tabular}{lcc}
\hline Property & Lab-scale melt & Industrial-scale melt \\
\hline YS (MPa) & 1530 & 1610 \\
UTS $(\mathrm{MPa})$ & 1890 & 1970 \\
El. $(25 \mathrm{~mm} \mathrm{GL)}(\%)$ & 14 & $13 \cdot 6$ \\
CVN impact energy at RT $(\mathrm{J})$ & 34 & $28-32^{*}$ \\
$K_{\text {IC }}(\mathrm{MPa} / \mathrm{m})$ & 120 & $90-110^{*}$ \\
\hline
\end{tabular}

*The property range is due to the properties obtained at various stages of processing of the ingot to hot-formed products.

Table 5. A comparison of mechanical properties in the softened condition.

\begin{tabular}{lccc}
\hline Steel & $\begin{array}{c}\text { YS } \\
(\mathrm{MPa})\end{array}$ & $\begin{array}{c}\text { UTS } \\
(\mathrm{MPa})\end{array}$ & $\begin{array}{c}\text { El. (\%) } \\
(25 \mathrm{~mm} \mathrm{GL})\end{array}$ \\
\hline $\begin{array}{l}\text { NiSiCrCoMo } \\
\left(740^{\circ} \mathrm{C} / 4 h, \text { Furnace cooled) }\right.\end{array}$ & 652 & 853 & $19 \cdot 4$ \\
$\begin{array}{l}250 \text {-grade Maraging } \\
\text { (Solution treated) }\end{array}$ & 725 & 1000 & 18.0 \\
\hline
\end{tabular}

NiSiCrCoMo steel processed on this scale are compared in table 4 with those derived from a laboratory-scale melt. The attractive combination of strength and toughness observed in the laboratory melt is seen to have been reproduced in the industrialscale melt.

\subsection{Machinability and formability}

Spheroidise-annealing $\left(740^{\circ} \mathrm{C}\right)$ softens the NiSiCrCoMo steel considerably. The properties of the steel in the spheroidise-annealed condition are, again, quite comparable to those of the 250-grade maraging steel in the solutionized condition (table 5). $\mathrm{NiSiCrCoMo}$ steel in the softened condition can easily be rough machined before finally subjecting to hardening and tempering treatment in order to develop an optimum combination of strength and fracture toughness.

The steel in the softened condition also possesses good formability. Erichsen cupping test yielded a cup depth of $10.8 \mathrm{~mm}$ for $2.3 \mathrm{~mm}$ sheet. In conformity with these observations, industrial trials of cold forming revealed that a $7 \mathrm{~mm}$ thick blank of $570 \mathrm{~mm}$ diameter could be formed, without intermediate annealing, to a shell of $350 \mathrm{~mm}$ inner radius.

\subsection{Weldability}

Gas tungsten-arc (GTA) process, generally recommended for low-alloy steels, has been chosen. Detailed studies were undertaken to arrive at a suitable filler material. Tension test results of burt-welded and heat-treated $2.3 \mathrm{~mm}$ thick sheet specimens revealed that the W2 filler (trade name of MIDHANI for the filler developed for 
250-grade maraging steel) yields $96 \%$ weld efficiency in terms of yield strength. Experiments have shown that the base metal strength could be realized in the butt-welded and heat-treated condition with base steel as filler. Efforts are now underway to process the base steel in the form of wires for use as filler.

The NiSiCrCoMo steel discussed in this presentation promises to be an inexpensive, and therefore attractive, substitute for expensive, high alloy steel like the wellknown maraging steel for light-weight, high performance structural applications.

\section{Acknowledgements}

The authors thank Mr S L N Acharyulu, Director, DMRL for encouragement. Thanks are due to Dr R D K Misra and Mr T V Balasubramanian for their help in conducting Auger studies and Dr K Muraleedharan for TEM studies. Dr R D K Misra helped in obtaining SIMS pictures. We are deeply grateful to $\mathrm{Mr}$ K K Sinha and Mr R K Mahapatra, former and present CMDs of MIDHANI, respectively, and their colleagues for their leadership in processing the tonnage-scale melts of the steel. We are grateful to Larsen and Toubro Limited, Bombay for weldability and formability studies.

\section{References}

Garrison W M Jr. 1986 Metall. Trans. A17 669

Ishii H, Kawarazaki T and Fujimora Y 1984 Metall. Trans. A15 679

Jolley W 1968 Trans. Metall. Soc. AIME 242306

Leslie W C 1972 Metall. Trans. 35

Lin T, Evans A G and Ritchie R O 1986 Acta Metall. 342205

Malakondaiah G, Srinivas M, Marthanda Murthy J and Rama Rao P 1994 Bull. Mater. Sci. 1773

Misra R D K and Rama Rao P 1993 Scr. Metall. Mater. 28513

Olson G B 1990 in Innovations in ultrahigh strength steel technology (eds) G B Olson, M Azrin and E S Wright, Proc. 34th Sagamore Army Materials Research Conference, 30 August-3 September, 1987, Lake George, New York. p. 3

Petch N J 1987 Acta Metall. 352027

Pickering F B 1978 in Physical metallurgy and design of steels (London: Applied Science Publishers Ltd)

Pink E, Mugschl E and Ortner B 1980 Proc. Fifth int. conf. strength metals and alloys (eds) P Haasen, V Gerold and G Kostorz (Oxford: Pergamon Press) Vol. 2, p. 1019

Ravi K V and Gibala R 1969 Scr. Metall. 3547

Rees W P, Hopkins B E and Tipler H R 1951 J. Iron Steel Inst. 169157

Rice J R and Johnson M A 1970 in Inelastic behaviour of solids (eds) M F Kanninen, W F Adler, A R Rosenfield and R I Jaffee (New York: McGraw Hill Book Co) p. 641

Ritchie R O and Thompson A W 1985 Metall. Trans. A16 233

Ritchie R O, Francis B and Server W L 1976 Metall. Trans. A7 831

Smialek R L, Webb G L and Mitchell T E 1970 Scr. Metall. 433

Srinivas M 1991 Fracture behaviour of iron, iron-based solid solutions and $F e-C-X$ alloys, Ph D Thesis, Banaras Hindu University, Varanasi

Srinivas M, Malakondaiah G and Rama Rao P 1991a Acta Metall. Mater. 39807

Srinivas M, Malakondaiah G and Rama Rao P 1991 b Proc. 6th int. conf. mech. behav. mater. (ICM6) Kyoto, Japan

Srinivas M, Malakondaiah G and Rama Rao P 1991c Proc. Joint FEFG/ICF int. conf. on fracture of engineering materials and structures, National University of Singapore, Singapore, 6-8 August 1991

Srinivas M, Malakondaiah G and Rama Rao P 1994a Proc. R. Soc. London 447223

Srinivas M, Sundararajan G, Malakondaiah G and Rama Rao P 1994b Proc. R. Soc. London 447237

Stoloff N S, Davies R G and Ku R C 1965 Trans. Metall. Soc. AIME 2331500

Tomita Y 1991 Mater. Sci. Tech. 7481 